\title{
ANALISIS PENGARUH KUALITAS PELAYANAN DAN PROMOSI TERHADAP KEPUASAN PELANGGAN YANG BERDAMPAK PADA LOYALITAS DI TUNAS TOYOTA CIPUTAT
}

\author{
Amirudin \\ Staf Pengajar Fakultas Ekonomi Universitas Pamulang \\ email: amirudin.alkayyis@gmail.com
}

\begin{abstract}
ABSTRAK
Penelitian ini bertujuan untuk mengetahui apakah ada pengaruh kualitas pelayanan dan promosi terhadap kepuasan pelanggan yang berdampak pada loyalitas di Tunas Toyota Ciputat. Berdasarkan penelitian yang telah ditetapkan, maka populasi yang dijadikan objek dalam penelitian ini adalah pelanggan Tunas Toyota Ciputat dengan sampel 50 orang. Metode yang digunakan dalam penelitian ini adalah metode penelitian kuantitatif karena data penelitian berupa angka-angka dan analisis menggunakan statistik dengan rancangan hipoteșis asosiatif yaitu mencari hubungan antara dua variabel atau lebih. Rancangan hipotesis ini adalah, $\mathrm{H}_{\mathrm{o}}$ artinya adalah tidak terdapat pengaruh kualitas pelayanan dan promosi terhađap kepuasan pelanggan yang berdampak pada loyalitas di Tunas Toyota Ciputat dan $\mathrm{H}_{\mathrm{a}}$ artinya terdapat pẹngaruh kualitas pelayanan dan promosi terhadap kepuasan pelanggan yang berdampak pada loyalitas di Tunas Toyota Ciputat. Rencana uji hipotesis dalam penelitian ini menggunakan distribusi nilai t. Bila $t$ hitung $>$ $\mathrm{t}_{\text {tabel }}$, maka $\mathrm{H}_{\mathrm{o}}$ ditolak dan $\mathrm{H}_{\mathrm{a}}$ diterima. Berdasarkan hasil perhitungan pengujian hipotesis secara parsial antara Variabel Kualitas Pelayanan $\left(X_{1}\right)$ terhadap Kepuasan Pelanggan (Y) sebesar 39,4\% terdapat pengaruh positif dan signifikan. Dari pengujian hipotesis menunjukkan $\mathrm{t}_{\text {bitung }}>\mathrm{t}_{\text {tabe }}(2,130>2,011)$. Yang berarti $\mathrm{H}_{0}$ ditolak dan $\mathrm{H}_{1}$ diterima. Pengujian hipotesis secara parsial antara Variabel Prọmosi (X ${ }_{2}$ ) terhadap Kepuasan Pelanggan (Y) sebesar $1,5 \%$ terdapat pengaruh positif dan signifikan. Dari pengujian hipotesis menunjukkan $t_{\text {hitun }}>\mathrm{t}_{\text {tabel }}(2,468>2,011)$. Yang berarti bahwa $\mathrm{H}_{0}$ ditolak dan $\mathrm{H}_{1}$ diterima, Perhitungan pengujian hipotesis secara simultan antara Variabel Kualitas Pelayanan $\left(X_{1}\right)$ dan promosi $\left(X_{2}\right)$ terhadap Kepuasan Pelanggan $(Y)$ diperoleh pengaruh yang positif dan signifikan. Dari persamaan $\mathrm{Y}=14,170+0,470 \mathrm{X}_{1}+0,169 \mathrm{X}_{2}$. dengan kontribusi sebesar $14,2 \%$ sisanya sebesar $85,8 \%$ dipengaruhi oleh dan $\mathrm{H}_{1}$ diterima. Hasil perhitungan pengujian hipotesis antara Variabel Kepuasan Pelanggan (Y) terhadap Loyalitas $(Z)$ sebesar $42,5 \%$ terdapat pengaruh positif. Dari pengujian hipotesis menunjukkan $t_{\text {hitung }}>t_{\text {tabel }}$ $(5,956>2,011)$. Yang berarti $\mathrm{H}_{\mathrm{o}}$ ditolak dan $\mathrm{H}_{1}$ diterima.
\end{abstract}

Kata kunci: kualitas pelayanan, promosi, kepuasan pelanggan dan loyalitas

\section{ABSTRACT}

This research aims to find out whether there is influence of the quality of service and promotion against the impact on customer satisfaction loyalty in Shoots Toyota Ciputat. Based on the research that has been defined, then the population which object in this research is a customer Shoots Toyota Ciputat with samples 50 people. The methods used in this research is quantitative research methods because the research data in the form of figures and analysis using statistics with associative design hypothesis that is looking for a relationship between two or more variables. The design of this hypothesis is, that there is no influence of the quality of service and promotion against the impact on customer satisfaction loyalty in Ciputat and Toyota Shoots means there is the influence of the quality of service and promotion against the impact on customer satisfaction loyalty in Shoots Toyota Ciputat. Plan test the hypothesis in this study $u$ sing distribution value $t$. When calculating $t>t$ table, then rejected and accepted. Based on the results of the calculation of hypothesis testing partially between service quality Variables $(X$ 1) toward customer satisfaction (Y) for 39.4\% there is a positive and significant influence. From hypothesis testing shows thitung $\rightarrow$ ttabel $(2,130>2,011)$. Which means it was rejected and accepted. Testing the hypothesis partially between Variables (X 2). Which means it was rejected and accepted. Testing the hypothesis partially between Variables $(X 2)$ against the Promotion of customer satisfaction (Y) of $1.5 \%$ there is a
positive and significant influence. From hypothesis testing shows thitung $>$ ttabel $(2,468>2,011)$. That positive and significant influence. From hypothesis testing shows thitung $>$ ttabel $(2,468>2,011$ ). That variable quality of service $(X 1)$ and promotion $(X)$ 2) toward customer satisfaction $(Y)$ obtained a positive and significant influence. Of the equation $Y=14,170+0,470 X 1+0,169 X 2$ with contributions amounting to $14.2 \%$ 85.8\% of the rest are influenced by other factors. From hypothesis testing shows Fhitung $>$ Ftabel (3.893> 2.81) means that rejected and accepted. The results of calculation of hypothesis testing between customer satisfaction Variable $Y$ ) against the loyalty (Z) amounted to $42.5 \%$ there is a positive influence. From hypothesis testing shows thitung $>$ ttabel (5,956 $>2,011)$. Which means it was rejected and accepted.

Keywords: quality of service, promotion, customer satisfaction and loyalty.

\section{PENDAHULUAN}

\section{A. Latar Belakang}

Pertumbuhan usaha yang

berkembang saat ini tidak terlepas dari persaingan yang kompetitif dalam upaya memenuhi harapan pelanggan. Penjualan dimulai dengan menjual produk atau jasa kepada calon pelanggan. Dan, 


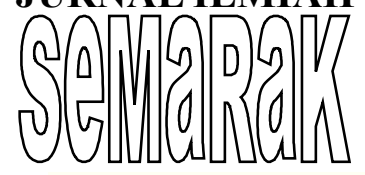

diperkirakan hampir setiap orang pernah melakukan penjualan, mulai dari barang pribadi, konsumsi dan lain sebagainya.

Penjualan dimulai dengan menjual produk atau jasa kepada calon pelanggan. Dan diperkirakan hampir setiap orang pernah melakukan penjualan, mulai dari barang pribadi, konsumsi dan lain sebagainya.

Setiap perusahaan di Indonesia dapat dikatakan sukses dengan adanya profit atau keuntungan yang didapatkan. Keuntungan dan profit tersebut didapat karena adanya konsumen atau pelanggan yang membeli barang maupun jasa tersebut, sebagai perusahaan yang melayani konsumen atau pelanggan, perusahaan tersebut harus mengetahui apa yang konsumen atau pelanggan harapkan dan apa yang pelanggan inginkan baik dari segi pelayanan maupun kemampuan dalam menawarkan barang atau jasa perbaikan kendaraan agar dapat menghasilkan kualitas pekerjaan yang maksimal dan memuaskan.

Perusahaan yang berorientasi pada produk berkeyakinan bahwa para pelanggan akan memilih produk yang berkualitas performa desain serta fiturfitur yang paling unggul.

Salah satu perusahaan dalam bidang penjualan dan pemasaran barang dan jasa adalah PT. Tunas Ridean Tbk yang bergerak di bidang penjualan dan layanan purna jual otomotif dengan merek seperti
Toyota, Daihatsu, BMW, dan sepeda motor Honda. Salah satu perusahaan Toyota adalah Tunas Toyota. Tunas Toyota memiliki 22 ruang pamer, 3 pusat perbaikan dan pengecatan kendaraan (boody \& paaint) dan 19 puusat laayanan puurnajual ddi wiilayah Jaakarta, Bannten, Bandung dan Lampung. Salah satunya adalah Tunas Toyota Ciputat, yang bertempat di Jl. Dewi Sartika no 187 Ciputat, Tangerang Selatan.

Showroom atau kantor cabang yang melayani pembelian mobil dan pelayanan purna jual atau bengkel (service dan body \& paint) Tunas Toyota Ciputat mempunyai visi menjadi penyedia solusi otomotif terbaik.

Bagaimana dengan area after sales Toyota? Ternyata kondisi yang ada menunjukkan bahwa ekspektasi pelanggan yang datang ke bengkel juga semakin meningkat, dari yang semula hanya mengharapkan agar kendaraannya sekedar selesai disevis di bengkel menjadi mengharapkan pula agar diberikan pelayanan dan fasilitas yang terbaik, dari mulai menu makanan ringan sampai free hotspot selama berada di bengkel tersebut.

Layanan purna jual atau sevis menjadi andalan Toyota untuk menjamin pelanggan Toyota dalam merawat kendaraannya, dan sangat percaya bahwa proses yang benar akan memberi hasil yang benar. Jangan hanya berkonsentrasi pada hasil, tetapi perbaiki prosesnya yaitu 
bagaimana pekerjaan dilakukan dan seberapa baik dan kompeten pelakunya.

Untuk mewujudkan tujuan menjadi penyedia solusi otomotif yang terbaik. Untuk memudahkan pelayanan servis pelanggan disarankan agar booking servis terlebih dahulu, minimal dua hari sebelum kedatangan. Manfaat booking adalah untuk menyiapkan teknisi, memastikan ketersediaan part, dan mendapatkan potongan biaya jasa, part dan material. Booking servis dapat dilakukan dengan cara telpon, sms, ataupun via email. Tetapi ada kalanya petugas booking kurang tanggap terhadap pelanggan yang datang maupun telepon untuk melakukan jadwal servis. Karena pelanggan mengeluhkan ketika telepon dan sms tidak langsung tanggap, sehingga kepuasan terhadap petugas booking berkurang, yang pada akhirnya pelanggan memilih untuk langsung datang ke bengkel.

Selama perusahaan berjalan pasti membutuhkan konsumen atau pelanggan dan konsumen membutuhkan perusahaan sebagai mitranya, seiring sejalan setiap perusahaan pasti ada persaingan atau sehingga perusahaan tersebut akan berusaha menjadi yang terbaik dalam bidangnya, masing-masing perusahaan harus meningkatkan kualitas pelayanan dalam melayani pelanggan agar pelanggan tetap setia dan loyal terhadap perusahaan tersebut. Maka dari itu dibutuhkan suatu penelitian untuk mengetahui tingkat pelayanan dalam rangka memenuhi kepuasan pelanggan.

Pelanggan merupakan aset berharga bagi seorang tenaga penjualan sehingga mengetahui karakter atau kepribadian dari calon pelanggan merupakan tugas utama dari tenaga penjualan. Ketika pelanggan dekat dengan anda, ciptakan rasa suka dengan membuat mereka merasa nyaman. Dengan perlakuan tersebut, pelanggan akan merasa dihargai dapat terjalin hubungan yang baik dengan pelanggan.

Selain itu penelitian ini juga akan berguna bagi perusahaan lain yang mengalami permasalahan yang sama dengan bengkel Tunas Toyota Ciputat. Untuk itu masalah yang ada dicarikan solusinya agar dapat terselesaikan melalui penelitian untuk mendapatkan kualitas yang lebih baik buat perusahaan dan karyawan.

Dalam penelitian ini penulis menggunakan kuesioner langsung yang diberikan kepada pelanggan yang rumahnya berada di wilayah Ciputat dan Pamulang dan telah melakukan servis sebanyak lima kali datang ke bengkel Tunas Toyota Ciputat dalam waktu delapan bulan.

Berdasarkan penjelasan yang diterangkan di atas, penulis berminat menjalankan penyelidikan dengan tajuk

“Analisis Pengaruh Kualitas Pelayanan Dan Promosi Terhadap Kepuasan Pelanggan Yang Berdampak Pada Loyalitas Di Tunas Toyota Ciputat".

\section{B. Perumusan Masalah}




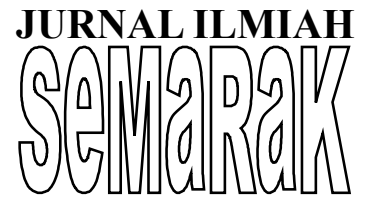

Beerdasarkan baatasan maasalah di aatas, makaa masaalah-masaalah peneliitian daapat dirumuskan sebagai berikut:

1. Apakah kualitas pelayanan berpengaruh posiitif dann siignifikan teerhadap kepuuasan peelanggan pada bengkel Tunas Toyota Ciputat.

2. Apakah promosi berpengaruh positif dan signifikan teerhadap kepuuasan pellanggan padda benngkel Tunas Toyota Ciputat.

3. Apakah kualitas pelayanan berpengaruh poositif daan siignifikan teerhadap loyalitas pada bengkel Tunas Toyota Ciputat.

4. Apakah promosi berpengaruh positif dan signifikan terhadap loyalitas pada bengkel Tunas Toyota Ciputat.

5. Apakah kuaalitas peelayanan daan proomosi beerpengaruh poositif daan siignifikan secara simultan terhadap kepuasan pelanggan pada bengkel Tunas Toyota Ciputat.

6. Apakah kepuasan pelanggan beerpengaruh poositif daan signnifikan teerhadap looyalitas paada beengkel Tunas Toyota Ciputat.

\section{Tujuan Penelitian}

Penelitian ini bertujuan untuk menguji dan menganalisis proses kegiatan yang dilakukan di bengkel Tunas Toyota Ciputat, yaitu :

1. Untuk menguji dan menganalisis kualitas pelayanan berpengaruh terhadap kepuasan pelanggan pada bengkel Tunas Toyota Ciputat.
2. Untuk menguji dan menganalisis promosi berpengaruh terhadap kepuasan pelanggan pada bengkel Tunas Toyota Ciputat.

3. Untuk meenguji daan meenganalisis kualitas pelayanan berpengaruh terhadap loyalitas pada bengkel Tunas Toyota Ciputat.

4. Untuk menguji dan menganalisis promosi beerpengaruh teerhadap looyalitas pada bengkel Tunas Toyota Ciputat.

5. Untuk menguji dan menganalisis kualitas pelayanan dan promosi berpengaruh secara simultan terhadap kepuasan pelanggan pada bengkel Tunas Toyota Ciputat.

6. Untuk menguji dan menganalisis kepuasan pelanggan berpengaruh terhadap loyalitas pada bengkel Tunas 7. Toyota Ciputat.

\section{TINJAUAN PUSTAKA}

\section{A. Manajemen}

Manajemen berasal dari kosa kaata baahasa Perancis kuuno, yaaitu menegement berarti seeni meelaksanakan daan mengaatur. Pengertian manajemen dari para ahli memiliki beberapa perbedaan namun maksud dan tujuannya sama .

Pengurusan adalah sains dan seni mengurus, menggunakan sumber manusia dan sumber-sumber lain dengan berkesan dan efisien untuk mencapai matlamat tertentu (Hasibuan (2002:2) 
Definisi manajemen menururt

Ricchard L.dDaft (2002:8), adalah pencapaian matlamat organisasi dengan cara yang berkesan dan cekap melalui merancang organisasi, kepimpinan, dan mengawal sumber organisasi .

Manajemen adalah aktifitas kerja yang melibatkan koordinasi dan pengawasan terhadap pekerjaan orang lain, sehingga pekerjaan tersebut dapat diselesaikan secara efisien dan efektif. (Stephen dan Mary, 2010).

Mary Parker Follet, mendefinisikan pengurusan sebagai seni melengkapkan kerja melalui orang lain. Takrif ini bermaksud bahawa seorang pengurus bertanggungjawab mengurus dan mengarahkan orang lain untuk mencapai matlamat organisasi .

Meenurut Danang Sunyoto (2012:1) manaajemen beerasal daari kata to manage, yaang arttinya mengurus, mengatur, melaksanakan dan mengelola. Istilah manajemen telah diartikan oleh beberapa pihak dengan perspektif yang berbeda, misalnya pengelolaan, pembinaan, pengurusan, kepemimpinan, administrasi dan sebagainya.

Menurut G.R Terry dalam (Ferdiansyah, 2014:7) pengurusan adalah proses atau rangka kerja, yang melibatkan bimbingan atau arahan dari sekelompok orang - orang ke arah tujuan organisasi atau niat - niat nyata .
Sementara menurut James Stoner maanajemen addalah "Prses pereencanaan, pengorganisasian, pengarahan, dan pengendalian usaha-usaha para anggota organisasi dan penggunaan sumbersumber lain yang wujud dalam organisasi, untuk mencapai matlamat yang dinyatakan .

$$
\text { Pelbagai pendapat tentang }
$$

pengertian pengurusan, antara lain, kewujudan mewujudkan sumber manusia, yang bermaksud pengurusan tenaga kerja dan ada orang yang menyamakan dengan pemahaman sumber daya manusia dengan personal (personel, staf, dan lain-lain) .

Diilihat daari defiinisi dii ataas dapatlah disiimpulkan baahwa manusia atau karyawan merrupakan fakktor terpenting sebagai motor penggerak dalam melaksanakan kegiatan usaha tersebut.

\section{B. Manajemen Pemasaran}

Pengurusan pemasaran adalah proses merancang dan melaksanakan pemikiran, harga, promosi, dan menyalurkan ide, barangan dan perkhidmatan untuk mewujudkan pertukaran yang memenuhi matlamat individu dan organisasi. (Philip Kotler, 2002: 9) .

Kotler dan Armstrong dalam bukunya Principles of Marketing (2006) mendefinisikan pengurusan pemasaran sebagai seni dan sains memilih pasaran sasaran dan membina hubungan yang 
saling menguntungkan dengan pasaranpasaran ini .

Definisi lain mengatakan bahawa pengurusan pemasaran adalah aktiviti menganalisis, merancang untuk melaksanakan, dan mengawasi semua aktiviti (program), untuk mendapatkan tahap pertukaran yang baik dengan pembeli sasaran untuk mencapai matlamat organisasi. (Buchari Alma, 2007: 130) .

\section{Kualitas Pelayanan}

Kualitas adalah totalitas fitur dan hubungan karakteristik produk atau jasa berdasarkan kemampuannya untuk memuaskan sendiri kebutuhan yang dinyatakan atau tersirat. Kualitas adalah keseluruhan ciri dan karakteristik suatu barang dan jasa yang berpengaruh pada kemampuannya untuk memuaskan kebutuhan yang dinyatakan maupun yang tersirat .

Kualitas total adalah kunci penciptaan nilai dan kepuasan pelanggan. Kualiatas merupakan tugas semua orang, seperti juga pemasaran adalah tugas semua orang .

Pelayanan adalah suatu tindakan untuk membantu menyelesaikan suatu masalah, yang dibutuhkan seorang pelanggan atau pelayanan untuk mengatasi masalah yang dihadapi supaya terciptanya kepuasan atas pelayanan yang diberikan .

Pelayanan pelanggan tidak berarti sekedar menjawab pertanyaan dan keluhan pelanggan, bahkan lebih dari pemecahan masalah yang timbul setelah pembelian .

Menurut Kotler, Philip (2002: 428), perkhidmatan atau perkhidmatan adalah apa-apa tindakan atau prestasi yang ditawarkan oleh pihak kepada pihak lain yang pada asasnya tidak ketara dan tidak menyebabkan sebarang pemindahan pemilikan. Pengeluaran adalah berkaitan dan mungkin tidak berkaitan dengan produk fizikal .

Menurut Tjiptono (2005: 87)

Perkhidmatan adalah tindakan atau tindakan seseorang atau organisasi untuk memberikan kepuasan kepada pelanggan. Perkhidmatan adalah produk yang ditawarkan dan dihantar kepada pelanggan yang memerlukannya secara meluas baik tangibles dan tidak berwujud .

Kualiti perkhidmatan adalah usaha untuk memenuhi keperluan dan keinginan pelanggan serta ketepatan penyerahannya dalam mengimbangi jangkaan pelanggan Tjiptono (2007) .

\section{Promosi}

Promosi adalah aktiviti mengkomunikasikan maklumat dari penjual kepada pelanggan atau pihak lain dalam saluran jualan untuk mempengaruhi sikap dan tingkah laku. Melalui promosi pengiklanan syarikat mengarahkan komunikasi yang persuasif untuk menargetkan pembeli dan orang ramai melalui media yang dipanggil media massa seperti surat khabar, majalah, 


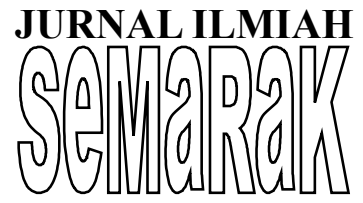

tabloid, radio, televisyen dan surat langsung (Baker, 2000:7) .

Sama dengan Sigit (2007: 101) Promosi adalah aktiviti syarikat yang direka untuk memberikan maklumat, memujuk dan mengingatkan pihak lain mengenai syarikat dengan barang dan perkhidmatan yang ditawarkan .

Untuk membina hubungan pelanggan yang baik, syarikat itu mesti merancang strategi komunikasi pemasaran (promosi) yang dapat meningkatkan nilai pelanggan .

Keller (2008) mendefinisikan, komunikasi pemasaran adalah alat yang digunakan dalam usaha untuk memaklumkan, memujuk, dan mengingatkan pengguna (secara langsung atau tidak langsung) mengenai produk dan jenama yang mereka jual .

Promosi memerlukan strategi untuk menggabungkan kaedah individu, seperti pengiklanan, promosi jualan dan promosi peribadi dalam kempen yang diselaraskan .

Menurut Grewal dan Levy (2008) promosi adalah komunikasi yang dilakukan oleh pemasar untuk berkomunikasi, memujuk dan mengingatkan pembeli berpotensi produk atau perkhidmatan untuk mempengaruhi pendapat pembeli dan mendapatkan tanggapan dari pembeli .

$$
\text { Walaupun Harini (2008: }
$$
berpendapat bahawa promosi adalah salah satu bentuk komunikasi, iaitu tahap khas untuk dapat merebut kesediaan untuk menerima daripada orang lain untuk idea, barangan dan perkhidmatan .

\section{E. Kepuasan Pelanggan}

Kepuasan adalah perasaan gembira atau kecewa kerana seseorang membandingkan prestasi produk yang dirasakan dengan jangkaan mereka. Kepuasan pelanggan adalah hasil yang dibeli oleh pembeli dari prestasi syarikat yang memenuhi jangkaan mereka. Pelanggan berpuas hati jika jangkaan mereka dipenuhi dan gembira jika jangkaan mereka melebihi. Pelanggan yang puas akan setia untuk lebih lama, membeli lebih banyak, kurang sensitif terhadap harga dan memberi ulasan yang baik tentang syarikat itu .

Kepuasan istilah merujuk kepada sikap umum seseorang terhadap karyanya. Seseorang yang mempunyai tahap kepuasan kerja yang tinggi menunjukkan sikap positif terhadap kerja

Kepuasan pelanggan menurut Irawan adalah "Hasil dari pelanggan terkumpul dalam menggunakan barang dan jasa". Pelanggan akan merasa puas jika mereka mendapat nilai atau faedah sesuatu item atau perkhidmatan. Menurut Phillip Kotler (2007: 36), kepuasan pelanggan adalah perasaan kesenangan atau kekecewaan seseorang yang datang dari perbandingan antara kesannya terhadap hasil (hasil) suatu produk dengan jangkaannya .

Menurut Umar (2010: 50), kepuasan pengguna adalah tahap perasaan pengguna 


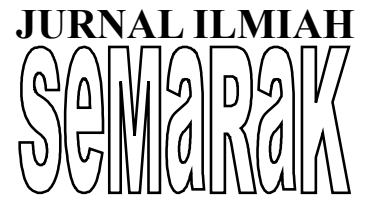

setelah membandingkan dengan jangkaan.

Selaras dengan kepuasan pelanggan, A. Parasuraman dan Lennard L. Berry mencadangkan "Terdapat lima dimensi kepuasan pelanggan, iaitu: tangibility, reliability, responsiveness, confidence and empathy" .

\section{F. Hipotesis Penelitian}

Hipotesis yang diuji dalam kajian ini berkaitan dengan kehadiran atau ketiadaan kesan yang signifikan dari satu set pembolehubah bebas ke atas pemboleh ubah bergantung. Hipotesis diuji seperti berikut :

1. $\mathrm{H}_{\mathrm{o}}$ : variabel kualitas pelayanan tidak berpengaruh terhadap kepuasan pelanggan.

$\mathrm{H}_{\mathrm{a}}$ : variabel kualitas pelayanan berpengaruh terhadap kepuasan pelanggan.

2. $\mathrm{H}_{\mathrm{o}}$ : variabel promosi tidak berpengaruh terhadap kepuasan pelanggan.

$\mathrm{H}_{\mathrm{a}} \quad$ : variabel promosi berpengaruh terhadap kepuasan pelanggan.

3. $\mathrm{H}_{\mathrm{o}}$ : variabel kualitas pelayanan tidak berpengaruh terhadap loyalitas.

$\mathrm{H}_{\mathrm{a}}$ : variabel kualitas pelayanan berpengaruh terhadap loyalitas.

4. $\mathrm{H}_{\mathrm{o}}$ : variabel promosi tidak berpengaruh terhadap loyalitas.

$\mathrm{H}_{\mathrm{a}}$ : variabel promosi berpengaruh terhadap loyalitas.

5. $\mathrm{H}_{\mathrm{o}}$ : variabel kualitas pelayanan dan promosi tidak berpengaruh signifikan terhadap kepuasan pelanggan.

$\mathrm{H}_{\mathrm{a}} \quad$ : variabel kualitas pelayanan dan variabel promosi berpengaruh signifikan terhadap kepuasan pelanggan.

6. $\mathrm{H}_{\mathrm{o}}$ : variabel kepuasan pelanggan tidak berpengaruh signifikan secara parsial terhadap loyalitas.

$\mathrm{H}_{\mathrm{a}}$ : variabel kepuasan pelanggan berpengaruh signifikan secara parsial terhadap loyalitas.

\section{METODE PENELITIAN}

Penelitian dilakukan pada Tunas Toyota Ciputat yang berlokasi di Jl. Dewi Sartika no. 187 Ciputat Tangerang Selatan.

Metode yang digunakan dalam penelitian ini adalah metode kuantitatif. Dengan menggunakan metode analisis path (jalur).

Populasi sasaran dalam penelitian ini adalah pelanggan yang servis di bengkel Tunas Toyota Ciputat selama delapan bulan antara Oktober 2016 sampai Juni 2017 sebanyak 50 orang yang telah melakukan servis. Sampel yang penulis masukkan dalam penelitian adalah sebanyak 50 orang pelanggan yang sudah melakukan servis kendaraan 


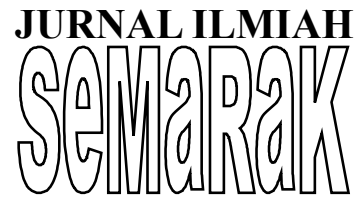

sebanyak lima kali datang ke bengkel Tunas Toyota Ciputat.

Pengumpulan data dilakukan dengan cara dokumentasi, wawancara dan kuesioner.

\section{HASIL DAN PEMBAHASAN}

\section{A. Gambaran Objek Penelitian}

Tunas Toyota merupakan bagian dari group otomotif terbesar di Indonesia, yaitu group Tunas Ridean. Tunas Toyota dioperasikan oleh PT. Tunas Ridean Tbk. Tunas Toyota memiliki 22 pusat layanan purna jual di wilayah Jakarta, Banten, Bandung dan Bandar Lampung. Tunas Toyota Ciputat adalah salah satu cabang dari Tunas Toyota group yang merupakan anak perusahaan dari PT. Tunas Ridean Tbk.

Sebelumnya Tunas Toyota Ciputat bernama Ciputat Supra Perkasa dan merupakan satu dari dua bengkel Toyota yang berada di wilayah Tangerang dan juga menjadi tempat teknisi latihan menjadi karyawan sebelum ditempatkan kebengkel Tunas Toyota yang lain. Pada tanggal 5 Maret 1989 PT Tunas Ridean Tbk mengganti nama dari Ciputat Supra Perkasa menjadi Tunas Toyota sebagai bengkel resmi Toyota yang merupakan bagian dari group Tunas dibawah PT Tunas Ridean Tbk.

Tunas Toyota Ciputat banyak melahirkan teknisi handal yang dapat dibanggakan untuk dialihkan atau dirotasi ke cabang lain yang membutuhkan tambahan teknisi. Seiring waktu pertumbuhan bengkel yang semakin banyak, Tunas Toyota Ciputat membatasi teknisi agar tidak pindah ke cabang lain tanpa alasan yang jelas dan dapat merugikan pihak cabang tanpa adanya pengganti yang setimpal.

Tunas Toyota selalu menyediakan pelayanan terbaik di berbagai tempat dan daerah untuk lebih mudah di jangkau lagi oleh pelanggan, dan Tunas Toyota Ciputat dalam menjaga pelanggannya agar selalu servis di Tunas Toyota Ciputat dengan memberikan potongan oli satu sampai dua liter yang dapat ditukar saat melakukan servis, bahkan promosi tersebut berlaku sampai 4 tahun atau $50.000 \mathrm{KM}$.

Tunas Toyota Ciputat juga menjalin kerjasama dengan perusahaan dan beberapa pengusaha rental serta taksi online Grab dibawah PT Transportasi Pengangkutan Indonesia untuk menservis kendaraannya agar tetap prima dalam melayani pelanggannya terutama mobil avanza sampai jangaka waktu tiga tahun, untuk yang memiliki kendaraan pribadi Tunas Toyota Ciputat memberikan discount khusus agar pengemudi tersebut datang kembali untuk melakukan servis.

Untuk menjamin pelayanan yang dapat mempermudah pelanggan melakukan perbaikan kendaaraan supaya mereka tidak terlalu lama menunggu saat servis, dengan tersedianya teknisi, suku cadang dan stall yang sudah tersedia yaitu 
JURNAL ILMIAH

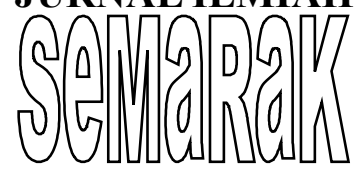

dengan melakukan Booking Service.

Booking dapat dilakukan pelanggan dengan telepon atau sms dihari sebelumnya. Hal ini merupakan nilai plus dari kualitas pelayanan Tunas Toyota Ciputat untuk memuaskan pelanggan.

Untuk menambah kualitas pelayanan, Tunas Toyota Ciputat menambah man power untuk mengingatkan pelanggan servis berkala secara teratur supaya kendaraannya tetap prima dan aman untuk dikendarai. Setelah di servis kendaraannya tiga hari kedepan pelanggan akan dihubungi oleh petugas untuk menayakan apakah kendaraannya setelah servis ada keluhan atau tidak dan untuk memastikan kualitas pelayanan pelanggan yang diberikan Tunas Toyota Ciputat benar-benar memuaskan.

Untuk memanjakan pelanggan dalam melakukan servis berkala dengan layanan cepat yaitu menggunakan sistem express maintenance yang dikerjakan oleh tiga orang untuk mempercepat proses pekerjaan yang semula butuh waktu dua jam untuk proses pekerjaan servis berkala, dengan adanya express maintenance waktu yang dibutuhkan untuk servis berkala tanpa keluhan cukup membutuhkan waktu satu jam untuk proses pekerjaan servis berkala sudah selesai dikerjakan.

\section{B. Penemuan dan Pembahasan}

\section{Pengaruh Secara Parsial}

a. Pengaruh Kualitas Pelayanan Terhadap Kepuasan Pelanggan

Besarnya pengaruh kualitas pelayanan terhadap kepuasan pelanggan adalah sebesar $39,4 \%$ dengan persamaan regresi $\mathrm{Y}=$ $26,369+0,394 \mathrm{X}_{1}$ bernilai positif dan signifikan. Hasil pengujian hipotesis diperoleh nilai $t_{\text {hitung }}$ lebih besar dari tabel $(2,130>2,011)$ maka $\mathrm{H}_{\mathrm{o}}$ ditolak dan $\mathrm{H}_{\mathrm{a}}$ diterima. Hasil ini didukung oleh hasil penelitian yang dilakukan oleh Muhammad Muzahid Akbar (2009), dimana hasil penelitiannya menyimpulkan bahwa kualitas pelayanan terhadap kepuasan konsumen mempunyai pengaruh positif dan signifikan.

Berdasarkan hasil penelitian diatas bahwa konsep kualitas pelayanan adalah suatu daya tanggap dan realitas dari jasa yang diberikan perusahaan. Kualitas pelayanan yang baik biasanya terlebih dahulu melihat kebutuhan pelanggan baru setelah itu dilakukan penyesuaian pelayanan apa yang tepat untuk pelanggan dan bagaimana pelaksanaan pelayanan yang dapat melahirkan kepuasan pelanggan. Jika semakin baik sikap pelayanan perusahaan maka akan menumbuhkan rasa kepuasan pelanggan dan pada akhirnya akan membentuk sikap pelanggan yang mengambil keputusan untuk 


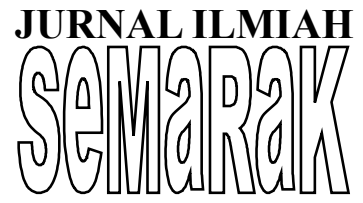

melakukan

Jurnal Semarak,Vol. 2,No.2, Juni 2019, Hal (1- 17)

@)Prodi Manajemen Fakultas Ekonomi Universitas Pamulang

perusahan tersebut.

\section{b. Pengaruh Promosi Terhadap Variabel Kepuasan Pelanggan}

Pengaruh promosi terhadap kepuasan pelanggan adalah sebesar $1,5 \%$ dengan persamaan regresi $\mathrm{Y}=$ $42,403+0,015 \mathrm{X}_{2}$ benilai positif dan signifikan. Hasil pengujian diperoleh nilai $t_{\text {hitung }}$ lebih besar dari $t_{\text {tabel }}(2,468>2,011)$. Maka $H_{o}$ ditolak dan $\mathrm{H}_{\mathrm{a}}$ diterima. Hasil ini didukung oleh hasil penelitian yang dilakukan oleh Irmal (2014), dimana hasil penelitiannya menyimpulkan bahwa variabel promosi terhadap variabel kepuasan pelanggan mempunyai pengaruh positif dan signifikan.

Berdasarkan hasil penelitian diatas bahwa bauran promosi menurut Kotler dan Amstrong (2010) adalah bauran promosi total sebuah perusahaan yang biasa disebut komunikasi pemasaran, terdiri dari bauran khusus dari periklanan (advertising), hubungan masyarakat (public relation), penjualan pribadi, (personal selling), promosi penjualan (sales promotion) dan alat-alat pemasaran langsung (direct marketing tools) yang perusahaan gunakan secara persuasif menyampaikan nilai pelanggan dan membangun hubungan dengan pelanggan. Intinya promosi adalah kegiatan mengkomunikasikan informasi dari penjual kepada pelanggan atau pihak lain dalam saluran penjualan untuk mempengaruh sikap dan perilaku. Jadi bila suatu perusahaan mempunyai program promosi agar segeara diumumkan dan disosialisasikan kepada internal karyawan dan tentunya informasi keluar seoptimal mungkin agar hasil yang ditargetkan dapat tercapai.

\section{c. Pengaruh Kualitas Pelayanan Terhadap Loyalitas}

Besarnya pengaruh kualitas pelayanan terhadap kepuasan pelanggan adalah sebesar $44,2 \%$ dengan persamaan regresi $\mathrm{Y}=$ $22,872+0,442 \mathrm{X}_{1}$ bernilai positif dan signifikan. Hasil pengujian hipotesis diperoleh nilai $t_{\text {hitung }}$ lebih besar dari $t_{\text {tabel }}(2,667>2,011)$ maka $\mathrm{H}_{o}$ ditolak dan $\mathrm{H}_{\mathrm{a}}$ diterima. Hasil ini didukung oleh hasil penelitian yang dilakukan oleh Hendi Suhandi (2014), dimana hasil penelitiannya menyimpulkan bahwa kualitas pelayanan terhadap loyalitas mempunyai pengaruh positif dan signifikan.

Menurut Kotler, Philip (2002:428), service atau pelayanan adalah setiap tindakan atau unjuk kerja yang di tawarkan oleh suatu pihak ke pihak lain yang secara prinsip intangible dan tidak menyebabkan perpindahan kepemilikan apapun. 
d. Pengaruh Promosi

\section{Loyalitas}

Pengaruh promosi terhadap kepuasan pelanggan adalah sebesar $6 \%$ dengan persamaan regresi $\mathrm{Y}=$ $38,892+0,060 \mathrm{X}_{2}$ benilai positif dan signifikan. Hasil pengujian diperoleh nilai $t_{\text {hitung }}$ lebih besar dari $t_{\text {tabel }}(2,289>2,011)$. Maka $H_{o}$ ditolak dan $\mathrm{H}_{\mathrm{a}}$ diterima. Hasil ini didukung oleh hasil penelitian yang dilakukan oleh Hendi Suhandi (2014), dimana hasil penelitiannya menyimpulkan bahwa variabel promosi terhadap variabel loyalitas mempunyai pengaruh positif dan signifikan.

Menurut Grewal dan Levy promosi merupakan komunikasi yang dilakukan oleh pemasar untuk mengkomunikasikan, membujuk dan mengingatkan pembeli potensial akan produk atau jasa untuk mempengaruhi opini pembeli dan memperoleh respon dari pembeli.

Sementara Harini (2008:71) berpendapat promosi adalah salah satu bentuk komunikasi, yaitu suatu tahap khusus untuk dapat merebut kesediaan menerima dari orang lain atas ide, barang maupun jasa.

\section{Pengaruh Secara Simultan}

\section{a. Pengaruh Kualitas Pelayanan dan Promosi Terhadap Kepuasan Pelanggan}

Berdasarkan hasil analisis pengaruh secara simultan atau bersama-sama variabel kualitas pelayanan dan promosi terhadap kepuasan pelanggan diperoleh pengaruh positif dan signifikan dengan persamaan regresi $\mathrm{Y}=$ $14,170+0,470 \mathrm{X}_{1}+0,169 \mathrm{X}_{2}$ dengan kontribusi sebesar $14,2 \%$ sedangkan sisanya sebesar $85,8 \%$ dipengaruhi oleh faktor lain. Dari pengujian hipotesis menunjukkan bahwa nilai $\mathrm{F}_{\text {hitung }}$ lebih besar dari $\mathrm{F}_{\text {tabel }}$ atau $(3,893>2,81)$. Maka $H_{o}$ ditolak dan $\mathrm{H}_{\mathrm{a}}$ diterima. Hasil ini didukung oleh hasil penelitian yang dilakukan oleh Hendi Suhandi (2014), dimana hasil penelitiannya menyimpulkan bahwa kualitas pelayanan dan promosi mempunyai pengaruh yang positif dan signifikan terhadap kepuasan pelanggan.

Kualitas pelayanan menurut Kotler (2000:83) adalah setiap tindakan atau kegiatan yang dapat ditawarkan oleh suatu pihak kepada pihak lain, yang pada dasarnya tidak berwujud dan tidak mengakibatkan kepemilikan apapun. konsep kualitas pelayanan adalah suatu daya tanggap dan realitas dari jasa yang diberikan perusahaan. Kualitas pelayanan yang baik biasanya terlebih dahulu melihat kebutuhan pelanggan baru setelah itu dilakukan penyesuaian pelayanan apa yang tepat untuk konsumen dan 


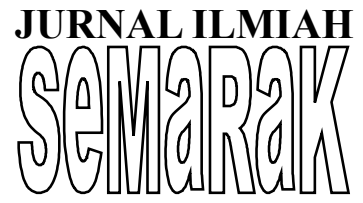

bagaimana pelaksanaan pelayanan yang dapat melahirkan kepuasan pelanggan.

\section{b. Pengaruh Kepuasan Pelanggan Terhadap Loyalitas}

Pengaruh kepuasan pelanggan terhadap loyalitas adalah sebesar $42,5 \%$ dengan persamaan regresi $\mathrm{Z}$ $=13,490+0,711 \mathrm{Y}$ bernilai positif dan signifikan. Dari hasil pengujian hipotesis diperoleh nilai $t$ hitung lebih besar dari $t$ tabel atau $(5,956>$ 2,011). Maka $\mathrm{H}_{o}$ ditolak dan $\mathrm{H}_{\mathrm{a}}$ diterima. Hasil ini didukung oleh hasil penelitian yang dilakukan oleh Hendi Suhandi (2014), dimana hasil penelitiannya menyimpulkan bahwa variabel kepuasan pelanggan terhadap variabel loyalitas mempunyai pengaruh positif dan signifikan.

Berdasarkan hasil penelitian diatas kepuasan adalah perasaan senang atau kecewa seseorang karena membandingkan kinerja yang dipersepsikan produk terhadap ekspektasi mereka. Sementara loyalitas pelanggan memiliki peran penting dalam sebuah perusahaan, mempertahankan mereka berarti meningkatkan kinerja keuangan dan mempertahankan kelangsungan hidup perusahaan.

Menurut Kotler (2007:36) kepuasan pelanggan dapat diciptakan melalui tiga faktor yaitu: mutu, pelayanan pelanggan dan nilai. Bila ketiga faktor ini memenuhi syarat maka kepauasan terhadap pelanggan akan terpenuhi.

\section{KESIMPULAN DAN SARAN}

\section{A. Kesimpulan}

Berdasarkan atas hasil penelitian dan analisa yang telah diuraikan pada bab sebelumnya oleh penulis tentang Analisis Pengaruh Kualitas Pelayanan dan Promosi Terhadap Kepuasan Pelanggan yang Berdampak pada Loyalitas di Tunas Toyota Ciputat, maka dapat disimpulkan oleh peneliti yaitu :

1. Kualitas pelayanan berpengaruh positif dan signifikan terhadap kepuasan pelanggan pada bengkel Tunas Toyota Ciputat sebesar $39,4 \%$ dengan persamaan regresi $\mathrm{Y}=26,369+$ $0,394 X_{1}$. Dari pengujian hipotesis diperoleh $t_{\text {hitung }}$ lebih besar dari $t_{\text {tabel }}$ atau $(2,130>2,011)$, dengan demikian $\mathrm{H}_{\mathrm{o}}$ ditolak dan $\mathrm{H}_{\mathrm{a}}$ diterima, yang artinya terdapat pengaruh positif dan signifikan antara kualitas pelayanan terhadap kepuasan pelanggan.

2. Promosi berpengaruh positif dan signifikan terhadap kepuasan pelanggan pada bengkel Tunas Toyota Ciputat sebesar $1,5 \%$ dengan persamaan regresi $\mathrm{Y}=42,403+$ $0,015 \mathrm{X}_{2}$. Dari pengujian hipotesis diperoleh $t_{\text {hitung }}$ lebih besar dari $t_{\text {tabel }}$ atau $(2,468>2,011)$, dengan demikian $\mathrm{H}_{\mathrm{o}}$ 


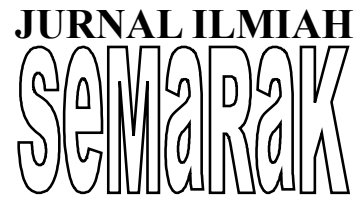

ditolak dan $\mathrm{H}_{\mathrm{a}}$ diterima yang artinya terdapat pengaruh positif dan signifikan antara promosi terhadap kepuasan pelanggan.

3. Kualitas pelayanan berpengaruh positif dan signifikan terhadap loyalitas pada bengkel Tunas Toyota Ciputat sebesar $39,4 \%$ dengan persamaan regresi $\mathrm{Y}=$ $22,872+0,442 \mathrm{X}_{1}$. Dari pengujian hipotesis diperoleh $t$ hitung lebih besar dari $t_{\text {tabel }}$ atau $(2,667>2,011)$, dengan demikian $\mathrm{H}_{\mathrm{o}}$ ditolak dan $\mathrm{H}_{\mathrm{a}}$ diterima, yang artinya terdapat pengaruh positif dan signifikan antara kualitas pelayanan terhadap loyalitas.

4. Promosi berpengaruh positif dan signifikan terhadap loyalitas pada bengkel Tunas Toyota Ciputat sebesar 1,5\% dengan persamaan regresi $\mathrm{Y}=$ $38,892+0,060 \mathrm{X}_{2}$. Dari pengujian hipotesis diperoleh $t_{\text {hitung }}$ lebih besar dari $t_{\text {tabel }}$ atau $(2,289>2,011)$, dengan demikian $\mathrm{H}_{\mathrm{o}}$ ditolak dan $\mathrm{H}_{\mathrm{a}}$ diterima yang artinya terdapat pengaruh positif dan signifikan antara promosi terhadap loyalitas.

5. Kualitas pelayanan dan promosi berpengaruh positif dan signifikan secara simultan terhadap kepuasan pelanggan pada bengkel Tunas Toyota Ciputat sebesar $14,2 \%$ dengan persamaan regresi $\mathrm{Y}=14,170+$ $0,470 X_{1}+0,169 X_{2}$. Dari pengujian hipotesis menunjukkan bahwa nilai $\mathrm{F}_{\text {hitung }}$ lebih besar dari $\mathrm{F}_{\text {tabel }}$ atau $(3,893$
$>$ 2,81), dengan demikian $\mathrm{H}_{\mathrm{o}}$ ditolak dan $\mathrm{H}_{\mathrm{a}}$ diterima. Artinya secara simultan atau bersama-sama terdapat pengaruh positif dan signifikan antara kualitas pelayanan dan promosi terhadap kepuasan pelanggan.

6. Kepuasan pelanggan berpengaruh positif dan signifikan terhadap loyalitas pada bengkel Tunas Toyota Ciputat sebesar 42,5\% dengan persamaan regresi $Z=13,490+0,711$ Y. Pengujian hipotesis diperoleh nilai $\mathrm{t}$ hitung lebih besar dari $t$ tabel atau $(5,956>2,011)$, dengan demikian $H o$ ditolak dan $H$ a diterima. Hal tersebut menunjukkan bahwa terdapat pengaruh yang positif dan signifikan antara kepuasan pelanggan terhadap loyalitas.

Dari apa yang peneliti teliti mengenai kepuasan pelanggan dan promosi kedua hal ini sangat berpengaruh terhadap kepuasan pelanggan, dimana ketika kualitas pelayanan dan promosi ditingkatkan dan sudah memuaskan maka loyalitas pelanggan akan mencapai tingkat yang memuaskan.

\section{B. Saran}

Penelitian ini memberikan sumbangsih saran bagi kemajuan Tunas Toyota Ciputat terutama dibidang pelayanan dengan saran-saran dalam peningkatan kualitas pelayanan dengan cara menambah pelatihan atau diskusi internal yang bertujuan untuk meningkatkan kemampuan pelayanan 
dalam mengatasi permasalahan yang dikeluhkan oleh pelanggan.

Saran masukan dari peneliti untuk Tunas Toyota Ciputat adalah:

1. Meningkatkan kemampuan analisa untuk kendaraan dengan keluhan sulit

2. Menambah promosi servis terhadap pelanggan

3. Mengontrol progres proses pekerjaan

4. Meningkatkan pendekatan kepada pelanggan

Secara global Toyota dikenal dengan Toyota Production System yang terkenal di perusahaan- perusahaan di seluruh dunia. Dalam sebagian besar kasus hasilnya tampak mengesankan secara ikhlas, tetapi secara keseluruhan mengecewakan. Apa yang hilang ialah "sistem manusia" yang kuat, yang bagi Toyota merupakan kandungan pokok bagi kemampuan bersaing dalam jangka panjang. Sistemsistem teknis dan sosial bekarja bersama untuk menciptakan budaya tim yang efektif guna memecahkan masalah. Sistem manusia didesain untuk menarik, mengembangkan, melibatkan, dan menginspirasi manusia untuk memecahkan masalah- masalah tersebut.

Dalam prakteknya Toyota juga mengenal istilah kaizen, yang berarti perbaikan terus menerus, melaksanakan kaizen adalah hal yang wajib dilakukan di lingkungan kerja agar selalu mendapatkan hasil yang maksimal, dengan mencari akar masalah dari kekurangan yang ada di bengkel, kemudian mencari solusi untuk

\begin{abstract}
perbaikan serta mengevaluasi setiap pelayanan dan promosi lainnya agar dapat selalu menarik minat pelanggan untuk servis secara rutin dengan tujuan pelanggan merasakan kepuasan yang berdampak pada loyalitas.
\end{abstract}

\section{DAFTAR PUSTAKA}

Abdullah, T, 2012, Manajemen Pemasaran, PT Rajagrafindo Persada, Jakarta

Ari Setiyaningrum, Jusuf Udaya, Efendi, 2015, Prinsip-Prinsip Pemasaran, Yogyakarta

Assauri, Sofjan, 2007, Manajemen Pemasaran, Rajawali Press, Jakarta

Buchari Alma, 2007, Manajemen Pemasaran dan Pemasaran Jasa, Alfabeta, Bandung

Christopher Lovelock, 2005, Manajemen Pemasaran Jasa, Kelompok Gramedia Indeks, Indonesia

Daft, Richard. L, 2002, Manajement, Edisi Kelima Jilid 1, Erlangga, Jakarta

Fajar Laksana, 2008, Manajemen Pemasaran, Pendekatan Praktis, Graha Ilmu, Yogyakarta

Gunawan Adisaputro, 2010, Manajemen Pemasaran, Analisis Untuk Perancangan Strategi Pemasaran, UPP STIM YKPN, Yogyakarta

Hasibuan, malayu S.P. 2002, Manajemen Dasar : Pengertian dan Masalah, Bumi Aksara, Jakarta

Jeffrey K. Liker, Michael Hoseus 2008 Toyota Culture : Jantung dan 


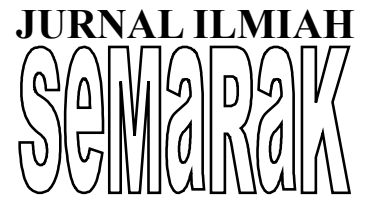

Jiwa Toyota, Toyota Way, Erlangga

Kotler, Philip, 2002, Manajemen Pemasaran Edisi Millenium 2 (Diterjemahkan oleh Hendra dan Ronny A.Rusli, PT.Prenhalindo, Jakarta

2005, Manajemen Pemasaran Jilid 1 dan 2, PT.Indeks, Jakarta

Lewis, Pamela S. Stephen H. Goodman, Patricia M. Fondt, 2004, Management; Challenges For Tomorrow's Leader", McGraw Hill

Nasution, M.N, 2004, Manajemen Jasa Terpadu, PT. Ghalia Indonesia, Jakarta

Rambat Lupiyoadi dan A. Hamdani 2008, Manajemen Pemasaran Jasa, Salemba Empat, Jakarta

Rangkuti, Freddy, 2003, Riset Pemasaran, PT. Gramedia Pustaka Utama, Jakarta

Ratminto, 2006, Manajemen Pelayananm Pustaka Pelajar, Yogyakarta

Riduwan, 2010, Metode dan Teknik Menyusun Tesis, Alfabeta Bandung

Saladin, Djaslim, 2003, Intisari Pemasaran dan Unsur Unsur Pemasaran, Cetakan Ketiga, Linda Karya, Bandung

Schiffman \& kanuk, 2004, Perilaku Konsumenm Edisi 7, Prentice Hall, Jakarta

Sofjan Assauri, 2009, Manajemen Pemasaran, Rajagrafindo Persada, Jakarta

Sugiono, 2003, Statistik Untuk Penelitian, Alfabet, Bandung , 2008, Metode Penelitian Bisnis, Alfabet, Bandung
Swasta, Basu, 2001, Manajemen Pemasaran I, Edisi ketiga, BPFE, Yogyakarta

, 2004, Manajemen Pemasaran : Analisa Perilaku Konsumen, Edisi Pertama Cetakan Ketiga, BPFE, Yogyakarta

Tjiptono, Fandy, 2008, Bauran Pemasaran Jasa, bayu Media, Jawa Timur

2008, Prinsip dan Dinamika Pemasaran, Edisi Pertama, Penerbit: J \& J Learning, Yogyakarta

Umar, Husein, 2003, Metodologi Penelitian Untuk Riset Skripsi dan Tesis Bisnis, Penerbit PT. Gramedia Pustaka Utama, Jakarta 